\title{
Venezuelan equine encephalitis virus infection causes modulation of inflammatory and immune response genes in mouse brain
}

\author{
Anuj Sharma ${ }^{\dagger 1,2}$, Bhaskar Bhattacharya ${ }^{\dagger 3}$, Raj K Puri ${ }^{3}$ and \\ Radha K Maheshwari*1
}

\begin{abstract}
Address: ${ }^{1}$ Centre for Combat Casualty and Life Sustainment Research, Department of Pathology, Uniformed Services University of the Health Sciences, Bethesda, Maryland, USA, ${ }^{2}$ Biological Sciences Group, Birla Institute of Technology and Science, Pilani, India and ${ }^{3}$ Tumor Vaccines and Biotechnology Branch, Division of Cellular and Gene Therapies, Center for Biologics Evaluation and Research, Food and Drug Administration, Bethesda, Maryland, USA

Email: Anuj Sharma - asharma@usuhs.mil; Bhaskar Bhattacharya - bhaskar.bhattacharya@fda.hhs.gov; Raj K Puri - raj.puri@fda.hhs.gov; Radha K Maheshwari* - rmaheshwari@usuhs.mil

* Corresponding author †Equal contributors
\end{abstract}

Published: 16 June 2008

BMC Genomics 2008, 9:289 doi:10.1/86/147|-2164-9-289
Received: 7 September 2007

Accepted: 16 June 2008

This article is available from: http://www.biomedcentral.com/I47I-2/64/9/289

(c) 2008 Sharma et al; licensee BioMed Central Ltd.

This is an Open Access article distributed under the terms of the Creative Commons Attribution License (http://creativecommons.org/licenses/by/2.0), which permits unrestricted use, distribution, and reproduction in any medium, provided the original work is properly cited.

\begin{abstract}
Background: Neurovirulent Venezuelan equine encephalitis virus (VEEV) causes lethal encephalitis in equines and is transmitted to humans by mosquitoes. VEEV is highly infectious when transmitted by aerosol and has been developed as a bio-warfare agent, making it an important pathogen to study from a military and civilian standpoint. Molecular mechanisms of VEE pathogenesis are poorly understood. To study these, the gene expression profile of VEEV infected mouse brains was investigated. Changes in gene expression were correlated with histological changes in the brain. In addition, a molecular framework of changes in gene expression associated with progression of the disease was studied.
\end{abstract}

Results: Our results demonstrate that genes related to important immune pathways such as

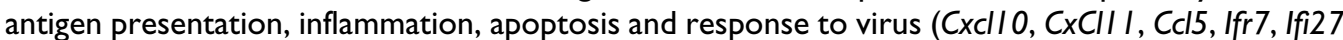
Oas Ib, Fcerg I,Mif, Clusterin and MHC class II) were upregulated as a result of virus infection. The number of over-expressed genes (>I.5-fold level) increased as the disease progressed (from 197, 296,400 , to 1086 at $24,48,72$ and 96 hours post infection, respectively).

Conclusion: Identification of differentially expressed genes in brain will help in the understanding of VEEV-induced pathogenesis and selection of biomarkers for diagnosis and targeted therapy of VEEV-induced neurodegeneration.

\section{Background}

Venezuelan equine encephalitis virus (VEEV) is an alphavirus in the family Togaviridae. It causes a highly virulent central nervous system (CNS) disease in horses and other equines and is transmitted to humans by mosquitoes. Outbreaks of VEEV have been reported at intervals of 2 to 10 years in South and Central America and in the
Texas region of North America, which has resulted in VEEV being included on the list of emerging pathogens [1]. VEEV has also been developed as a bio-warfare agent, making its use more likely than other non-weaponized agents in the event that a bio-weapon or bio-terrorism agent is used [2]. There is no specific treatment available for VEEV. A vaccine for prophylaxis against VEEV is under 
Table I: Progression of disease and mortality in VEEV infected mice.

\begin{tabular}{|c|c|c|c|c|c|c|c|c|c|c|}
\hline \multirow[t]{2}{*}{ Disease Progression } & \multicolumn{10}{|c|}{ Day(s) Post Infection } \\
\hline & 0 & I & 2 & 3 & 4 & 5 & 6 & 7 & 8 & 9 \\
\hline Roughening of Fur & 0 & 0 & 5 & 9 & 9 & 8 & 5 & I & I & - \\
\hline Hunched Posture/Lethargic/Shivering & 0 & 0 & 0 & 0 & 9 & 8 & 5 & I & 1 & - \\
\hline Hind Limb Paralysis & 0 & 0 & 0 & 0 & I & 8 & 5 & 1 & 1 & - \\
\hline Death & 0 & 0 & 0 & 0 & 0 & I & 3 & 4 & 0 & I \\
\hline Total died/Total No. & $0 / 9$ & $0 / 9$ & $0 / 9$ & $0 / 9$ & $0 / 9$ & $1 / 9$ & $4 / 9$ & $8 / 9$ & $8 / 9$ & $9 / 9$ \\
\hline$\%$ Mortality & 0 & 0 & 0 & 0 & 0 & 11.1 & 44.4 & 88.8 & 88.8 & 100 \\
\hline MST (Day) & 6.66 & & & & & & & & & \\
\hline
\end{tabular}

Mice were infected with 1000 pfu of $\mathrm{V} 3000$ in left rear foot pad at day 0 and were monitored for the clinical symptoms of disease thereafter. All the animals exhibited hind limb paralysis, a hallmark of VEEV infection and succumbed to disease by day 9 post infection. Mortality was $100 \%$ with a mean survival time of 6.6 days.

investigational new drug status and is given to personnel at risk of occupational exposure to VEEV. This vaccine has several limitations and has not been licensed by the FDA. VEEV infection in mice induces the bi-phasic disease observed in equines and lethal human infections ( $0.5 \%)$ thus making it a good model to study VEEV pathogenesis $[3,4]$. VEEV spreads from the site of inoculation through the locally draining lymph nodes, causes viremia, and disseminates to other lymphoid organs [5]. Viremia is followed by a CNS phase of disease [6-8]. VEEV enters into the CNS primarily through the olfactory neuroepithelium, via brain capillary endothelial cells and the trigeminal nerve $[7,9]$. In the CNS, VEEV infects neurons and glial cells and causes subsequent cellular degeneration. Infection with VEEV results in neuronal cell death, active gliosis and an intense inflammatory response characterized by perivascular and interstitial mononuclear cell infiltration [4,5,10-13]. However, in another subset of dying neurons associated with astrogliosis, no VEEV antigen can be found, indicating an alternate, indirect mechanism of neuronal degeneration $[11,13]$.

As the mechanism(s) underlying the inflammatory and immune response to VEEV infection in brain and subsequent neurodegenration are poorly understood, it is important to characterize the underlying cellular and molecular pathways. To fulfill this objective we used the virulent neuroinvasive strain, V3000, of VEEV. Gene expression changes in VEEV-infected mouse brain were studied using microarrays containing 16,463 oligonucleotides, representing 15,000 genes. We demonstrate that with the progression of disease both the total number of genes and fold expression of numerous genes increased. Many of the changes were associated with important immune pathways such as antigen presentation, inflammation, apoptosis and viral response. Gene expression changes were validated by RT-PCR. Pathologic changes in the brain were documented by H\&E (hematoxylin and eosin) and immunohistochemistry (IHC).

\section{Results}

Survival of animals post VEEV infection

Mice began showing roughening of fur and hunched back at day 2 post infection. By day 4, animals were lethargic and at least one mouse had hind limb paralysis. One animal died on day 5 post infection and all other animals showed little or no movement. All the mice died by day 9 post infection. Mortality was $100 \%$ with mean survival time of 6.6 days. Animal mortality is documented in Table 1.

\section{Histopathology and immunohistochemistry for VEEV antigen}

VEEV antigen-specific staining showed the presence of viral antigen within neurons and glial cells in the olfactory and prefrontal areas of the brain at $48 \mathrm{hr}$ post infection. Many more VEEV infected neurons and glial cells were present throughout the brain at $72 \mathrm{hr}$ post infection. VEEV antigen was present throughout the brain at $96 \mathrm{hr}$ post infection and the degree of inflammation corresponded to the density of virus infected cells. Inflammation started with perivascular cuffing and localizaton to the meninges at $48 \mathrm{hr}$ post infection. At $72 \mathrm{hr}$ post infection, inflammation was observed in the olfactory and frontal area of the brain. By $96 \mathrm{hr}$ post-infection inflammation was extensive and had spread throughout the brain (Fig 1).

\section{Gene expression analysis}

Microarrays were performed using RNA extracted from VEEV-infected mouse brain at $24 \mathrm{hr}, 48 \mathrm{hr}, 72 \mathrm{hr}$ and 96 hr post infection and gene expression profile were compared with RNA extracted from saline infected control mice at similar time points. All the biological replicates (duplicates for each time point) shared significant homology in gene expression (correlation coefficient $\geq 0.80$ ). Mean fold-expression of biological replicates $\geq 1.5$ fold over control was determined to be significant. As shown in Table 2, the number of genes upregulated in brain increased as disease progressed (Fig 1). At $96 \mathrm{hr}$ post infec- 


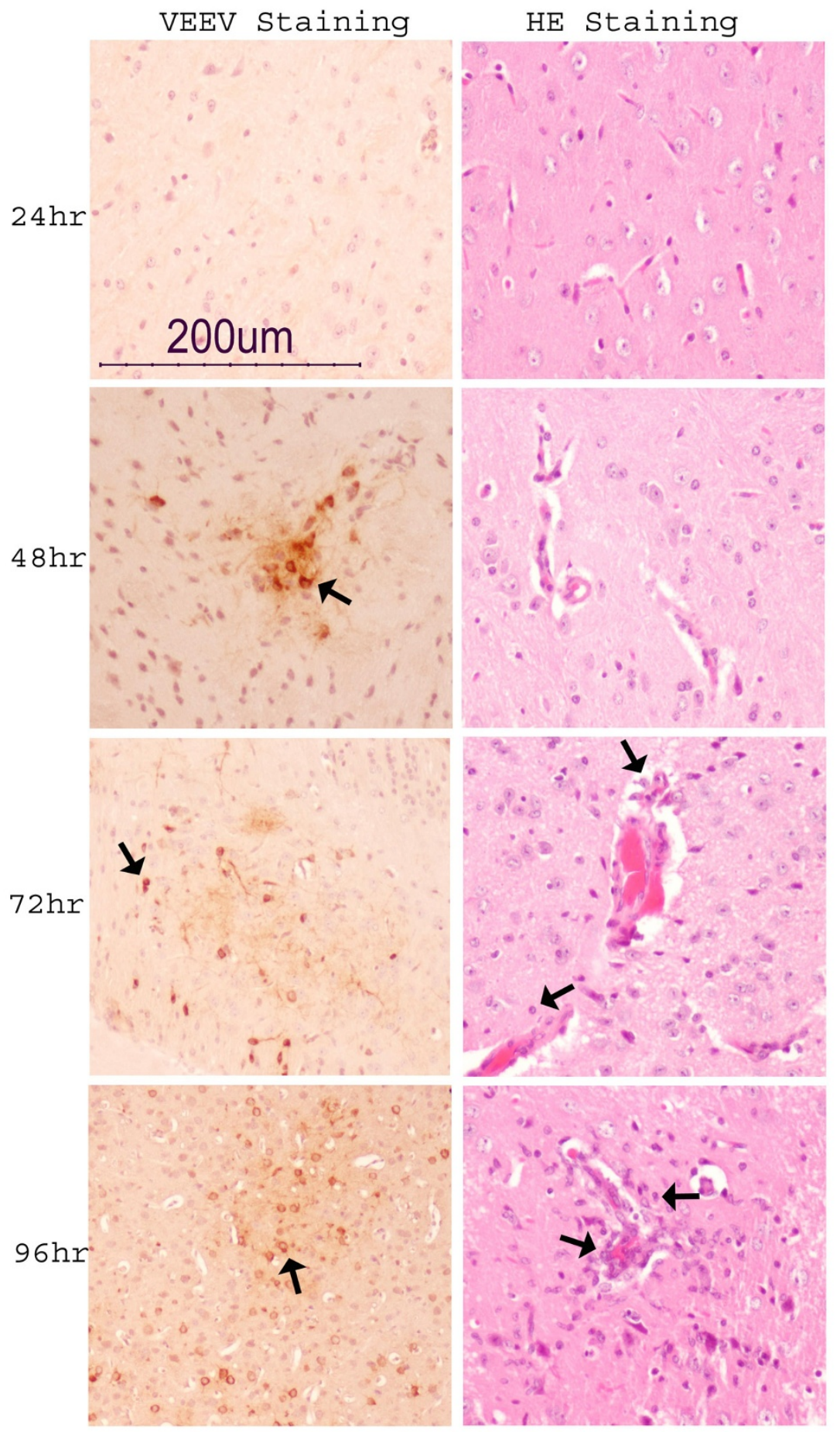

Figure I

Evidence of VEEV infection in mouse brain. Mouse brains at various time points after VEEV infection were analyzed by H\&E and IHC staining. VEEV appeared in brain at $48 \mathrm{hr}$ post infection (indicated by arrows), which was accompanied by the initiation of inflammation in brain as evident by vessel thickening and endothelial cuffing. At $72 \mathrm{hr}$ post infection VEEV antigen can be detected throughout the mid-brain. Inflammation was evidenced by increased endothelial cuffing and neutrophil infiltration (indicated by arrows). Inflammation was extensive throughout the brain along with increased VEEV antigen in brain at 96 hr post infection. 
Table 2: Total Genes Upregulated in VEEV Infected Mice brain.

\begin{tabular}{ccccc}
\hline Time, Hour(s) pi & $>5.0$ folds & $>3.0-5.0$ folds & Total genes over-expressed & I.0 folds \\
\hline 24 & 6 & 18 & 183 & 292 \\
48 & 3 & 27 & 212 & 322 \\
72 & 53 & 148 & 960 & 413 \\
96 & 33 & 129 & 1122
\end{tabular}

Total RNA extracted from VEEV infected brain was analyzed by microarray as described in methods. Gene's upregulated $\geq 1.5$ folds were considered. Number of genes over expressed increased as the disease progressed with maximum genes over expressed at 96 hr post infection.

tion the maximum numbers of total genes were upregulated at $\geq 1.5$ fold levels in mouse brain.

To analyze similarities and difference in gene expression between brains at different time points, hierarchical clustering analysis was done for all genes at the four time points. Genes which showed a distinct pattern of overexpression with the time of VEEV infection are shown in Fig 2. All genes were grouped in two clusters. The first cluster contained genes upregulated at $24 \mathrm{hr}$ and $48 \mathrm{hr}$, whereas the second cluster contained genes upregulated at $72 \mathrm{hr}$ and $96 \mathrm{hr}$ post infection. This analysis clearly distinguished the changes in the gene expression profile with the progression of VEEV infection. Some genes related to the inflammatory response, such as $\mathrm{Cxcl10}$, Clu and antigen presentation, such as B2m, Fcer1g showed overexpression only at 72 and $96 \mathrm{hr}$ post infection (Fig 2).

Functional analysis of over-expressed genes was performed using the GOFFA (gene ontology for functional analysis) library of the Arraytrack software. Genes belonging to various biological processes were grouped together. Based on these analyses, a majority of genes (164, 251, $759,928)$ were identified to play a role in different biological processes at $24 \mathrm{hr}, 48 \mathrm{hr}, 72 \mathrm{hr}$, and $96 \mathrm{hr}$ post infection, respectively. These genes were further categorized by the various functions that may play an important role in VEEV pathogenesis (Fig 3) as follows:

\section{i) Virus response genes}

It has been shown that interferon and interferon-inducible genes play an important role in the immune response towards viral pathogens. Consistent with this information, several interferon-inducible genes were upregulated (Table 3) in present study. These include Ifi27, Ifih1, Irf7 and Oas $1 b$ which were upregulated at $72 \mathrm{hr}$ and $96 \mathrm{hr}$ post infection except Becn1 that was over-expressed only at 72 hr post infection, and Spn which was over-expressed at all time points.

\section{ii) Inflammatory response genes}

Inflammation constitutes an important part of the immune response towards the invading pathogen. In VEEV infection, inflammation in brain is implicated in the secondary neuronal damage leading to morbidity and mortality. Several genes related to the inflammatory response were upregulated in the brain following VEEV infection, mostly at 72 and 96 hr post infection (Table 3). Most importantly, chemokine genes e.g., Cxcl9, Cxcl10, Cxcl11, Cxcl13, Ccl3, Ccl5 and Ccl12 that exert a chemotactic signal for the immune cell migration to the site of the injury were upregulated at 72 and $96 \mathrm{hr}$ post infection. These gene expression correlates with the increased neutrophil infiltration in brain and blood brain barrier (BBB) compromise (Fig 1). In addition inflammatory genes e.g., Fcer $1 g$, and Mif were also over-expressed at 72 and $96 \mathrm{hr}$ post infection. (Table 3)

iii) Genes involved in antigen presentation (AP)

Resident glial cells of the brain are known to act as antigen presenting cells and constitute an important part of the immune response against a virus pathogen. Several major histocompatibility complex (MHC) class II genes e.g., H2D1, H2-D4 H2-Q7 and H2-T23 were upregulated at $72 \mathrm{hr}$ and 96 hr post infection, concomitant with VEEV antigen appearance in the brain. MHC class I receptors such as $C d 1 d 1, B 2 m$ and $A p 3 d 1$ were also upregulated at $96 \mathrm{hr}$ post infection. (Table 3 )

\section{iv) Apoptotic gene expression}

Apoptotic neurons were seen in the VEEV-infected mouse brain in regions associated with VEEV antigen and the regions of gliosis that are free of VEEV antigen. Several apoptotic genes such as caspase recruitment domain (Card)14, fas apoptotic inhibitory molecule (Faim)2, Apoptosis-associated tyrosine kinase (Aatk), eukaryotic translation initiation factor 5 (Eif5a) and myeloid cell leukemia sequence 1 (Mcl1) were upregulated at $72 \mathrm{hr}$ and $96 \mathrm{hr}$ post infection (Fig 3). Few genes, like amyloid beta (A4) precursor protein (App), bcl2/adenovirus e1b interacting protein 3-like (Bnip3l), baculoviral IAP repeatcontaining 6 (Birc6) and Spn were upregulated throughout the study and few others such as amyloid beta (A4) precursor-like protein 1 (Aplp1), Clusterin (Clu), integral membrane protein 2B (Itm $2 b$ ), and valosin containing protein $(V c p)$, were upregulated as early as $48 \mathrm{hr}$ post infection (Table 4).

Apart from over-expressed genes, few genes were downregulated ( $\leq 2$ fold) at all time points. Those genes are 


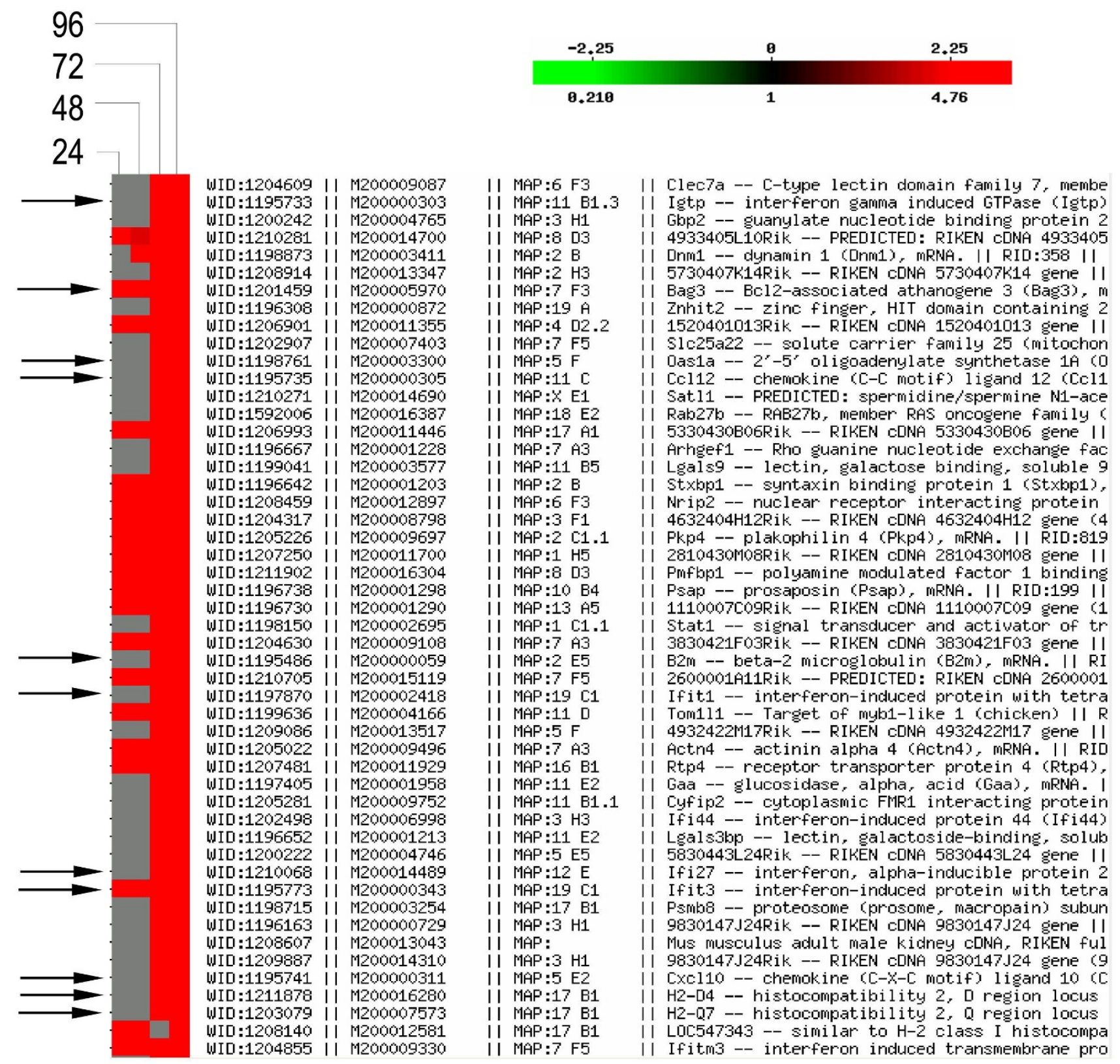

Figure 2

Hierarchical clustering of gene expression in mouse brain after VEEV infection. All over-expressed genes were clustered; however, a snap shot of selected genes is shown due to space limitation. Genes that are marked with arrows are over expressed $\geq 2.0$ fold at 72 and $96 \mathrm{hr}$ post infection. Color indicates the relative expression level of each gene in VEEV infected brain over saline treated control mouse brain, with red indicating higher expression, grey indicating absence of expression and darker red color indicating over expression but at a lower level.

listed in supplementary table 1 . As expected, the functional analysis showed genes related to several cellular physiological processes such as cell transport (Atp5j2, Slc18a2, Actr6, Timm8b) cell cycle/division (Cetn3), cellular metabolism (Zfp99, Rpl37a, Pigf, Snrpe, Rps26, Rps12, Rpl39, Rpl26, Rpl30, Cox7c, Ndufc1, Mrps33 and Ppia) and other cellular processes (stmn3, Pvalb, Pcp4, Usmg5) were down-regulated in VEEV infection.

\section{Confirmation of gene expression}

Randomly selected genes identified in the microarrays were analyzed by semi-quantitative RT-PCR analysis in 3- 


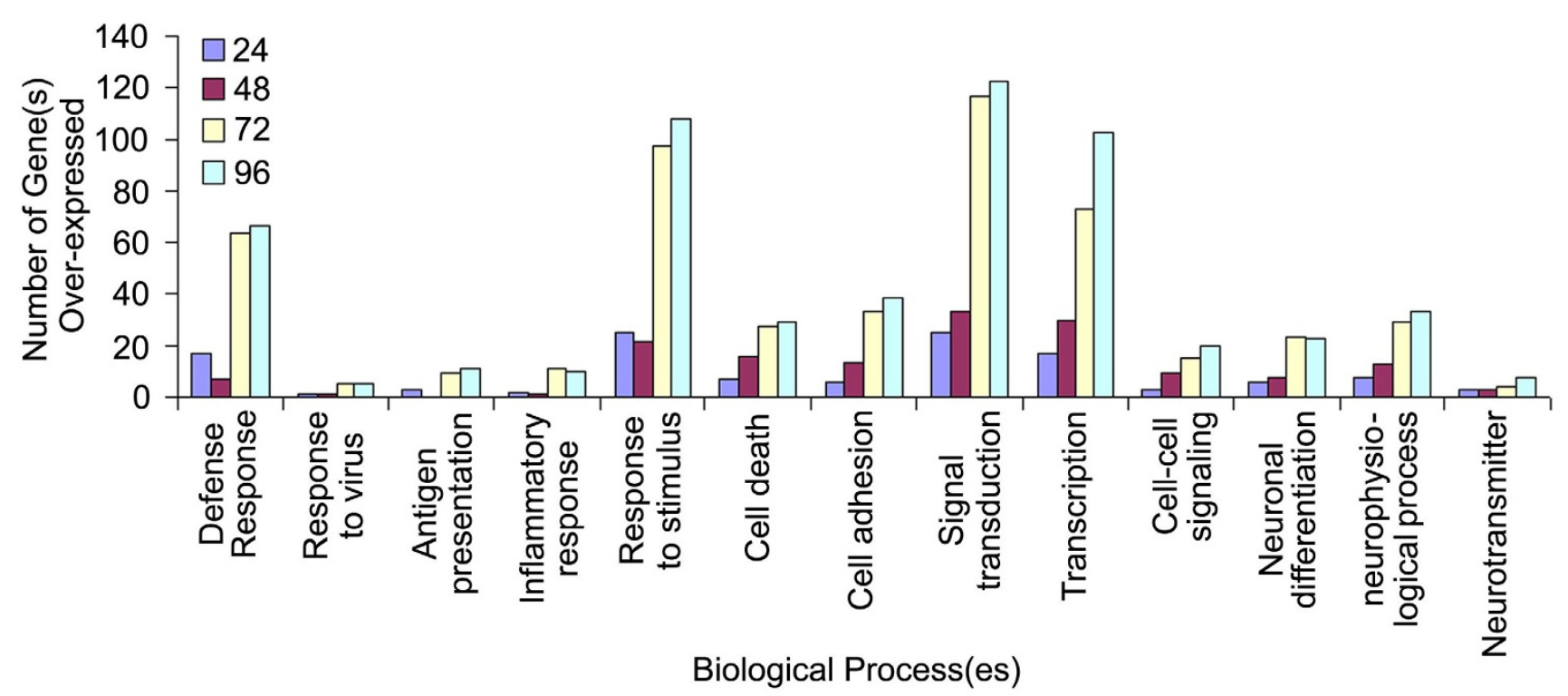

Figure 3

Analysis of molecular pathways in VEEV infected brain. Number of genes involved in various pathways of biological processes was analyzed by GOFFA Library of Arraytrack software. Genes involved in the various biological processes increased with the progress of the disease.

4 biological replicates. Specific amplification was confirmed by sequencing PCR products as described in materials and methods (data not shown). As shown in Fig 4, the expression of genes Oas1b, Fcre $1 \mathrm{~g}$ and Clu was up-regulated in mouse brain infected with VEEV. Although RTPCR analysis was not quantitative, consistent with microarray analysis, gene expression of Fcer $1 g$, Oas $1 b$ and $\mathrm{Clu}$ was higher at 48, 72 and $96 \mathrm{hr}$ post infection as compared to saline control and 24 hr post infection (Fig 4)

\section{Discussion}

The proximal cause of death following VEEV infection is attributed to the host immune response to replicating virus resulting in lethal encephalitis [8]. Therefore, it is important to study the kinetics of changes in gene expression in the brain of the VEEV infected host to understand the resulting immune response and to identify potential therapeutic targets and markers for treatment of VEEV infection. In the present study, total RNA isolated from mouse brain was used. This consisted of RNA from all the cell types present in the VEEV infected mouse brain. The goal of the study was to characterize the overall molecular frame work of gene expression in the brain. In this way, the changes in gene expression could be directly correlated with the tissue pathology. Since different cell types, individually, may respond differently to VEEV infection it is imperative to study the overall gene expression patterns during disease progression in tissue containing all the relevant cells.
Consistent with the histopathological changes, microarray analysis showed over-expression of the genes involved in the various immune responses towards the pathogen. For example Oas1b, Ifi27, Ifih1 and Irf7 genes were up-regulated at 72 and $96 \mathrm{hr}$ post infection. Elevated level of Oas $1 b$ has been shown to inhibit West Nile virus (WNV) replication by reducing the positive strand viral RNA level in cells [14]. Since VEEV is a positive single strand RNA virus, increased Oas $1 b$ levels may also potentially inhibit VEEV replication. The anti-VEEV activity of interferon (IFN) and interferon regulatory factor (IRF) is also well established $[15,16]$. IFN $\alpha / \beta$ knockout mice showed increased and early spread of VEEV into brain, and IRF2 knockout mice showed increased susceptibility to otherwise avirulent strains of VEEV [17].

The ability of microglia, the brain's resident macrophage, to present antigen associated with MHC class II to T cells, allows these normally quiescent cells to play a critical role in shaping the outcome of many neurological diseases $[18,19]$. Activated glial cells are observed in the brains of VEEV-infected mice $[10,11]$. Consistent with these reported observations, upregulated MHC class II loci genes such as H2-D1, H2-D4 H2-Q7 and H2-T23 in the present study may reflect the activated state of glial cells in the brain of VEEV infected mice. Several molecules associated with MHC-I-mediated presentation such as $B 2 m$, Fcerg1 and Cd1d1 were also upregulated in our study. Beta 2 microglobulin $(B 2 m)$ was also upregulated in acquired 
Table 3: Genes involved in virus response, inflammatory response and antigen presentation

\begin{tabular}{|c|c|c|c|c|c|}
\hline \multirow[t]{2}{*}{ UniGene ID } & \multirow[t]{2}{*}{ Functional Grouping (Gene) } & \multicolumn{4}{|c|}{ Upregulation (fold change) (Hours post infection) } \\
\hline & & 24 & 48 & 72 & 96 \\
\hline & Virus Response and Inflammation & & & & \\
\hline Mm. 136224 & Interferon induced with helicase $\mathrm{C}$ domain I (Ifih I) & NE & $3.59 /-$ & $5.21 \pm 1.05$ & $4.18 \pm 0.31$ \\
\hline Mm.3233 & Interferon regulatory factor 7 (Irf7) & NE & NE & $4.31 \pm 1.51$ & $2.01 \pm 0.08$ \\
\hline Mm.27I275 & Interferon, alpha-inducible protein 27 (Ifi27) & NE & NE & $4.79 \pm 0.67$ & $6.62 \pm 0.32$ \\
\hline Mm.23347I & 2'-5' oligoadenylate synthetase IB (Oas Ib) & NE & $1.89 /-$ & $5.12 \pm 0.04$ & $2.32 \pm 0.08$ \\
\hline Mm.867 & Chemokine (C-C motif) ligand I2 ( $\mathrm{Ccll} 2)$ & $5.03 \pm 1.86$ & $4.63 /-$ & $7.87 \pm 0.54$ & $4.70 \pm 0.36$ \\
\hline Mm. 131723 & Chemokine (C-X-C motif) ligand II (Cxcl I I) & $\mathrm{NE}$ & $8.76 /-$ & $17.02 \pm 5.19$ & $|3.68 \pm 5.5|$ \\
\hline Mm.877 & Chemokine (C-X-C motif) ligand I0 (Cxcl I0) & NE & $7.49 /-$ & $15.45 \pm 0.67$ & $8.69 \pm 0.37$ \\
\hline Mm.284248 & Chemokine (C-C motif) ligand 5 (Ccl5) & NE & NE & $4.27 \pm 1.27$ & $3.56 \pm 0.66$ \\
\hline Mm. I 282 & Chemokine (C-C motif) ligand $3(\mathrm{Ccl} 3)$ & $\mathrm{NE}$ & NE & $2.26 / 1.83$ & $2.05 \pm 0.21$ \\
\hline Mm.10116 & Chemokine (C-X-C motif) ligand I 3 (Cxcl I3) & NE & NE & $2.06 \pm 0.41$ & I.73/- \\
\hline Mm.766 & Chemokine (C-X-C motif) ligand 9 (Cxcl9) & NE & NE & $3.99 \pm 1.62$ & $1.85 \pm 0.14$ \\
\hline Mm.22673 & Fc receptor, IgE, high affinity I, gamma polypeptide (Fcer Ig) & NE & NE & $3.66 \pm 0.29$ & $3.38 \pm 0.63$ \\
\hline Mm.5419 & Interleukin I7 (III7) & NE & NE & NE & $2.06 \pm 0.33$ \\
\hline Mm.2326 & Macrophage migration inhibitory factor (Mif) & NE & $1.08 \pm 0.17$ & $2.25 \pm 0.53$ & $2.06 \pm 0.07$ \\
\hline Mm.24I63 & PYD and CARD domain containing (Pycard) & NE & NE & $1.81 \pm 0.165$ & $1.52 \pm 0.31$ \\
\hline Mm.200608 & Clusterin (Clu) & NE & $1.74 \pm 0.13$ & $4.03 \pm 1.54$ & $2.45 \pm 0.37$ \\
\hline \multirow[t]{2}{*}{ Mm.2837।4 } & Sialophorin (Spn) & $1.93 \pm 0.14$ & $2.50 \pm 0.19$ & $2.87 \pm 1.63$ & $2.25 \pm 0.24$ \\
\hline & Antigen Presentation & & & & \\
\hline Mm.209294 & Adaptor-related protein complex 3 , delta I subunit (Ap3dI) & $1.33 \pm 0.83$ & NE & $2.17 \pm 0.35$ & $1.69 \pm 0.01$ \\
\hline Mm. 163 & Beta-2 microglobulin (B2m) & NE & NE & $10.39 \pm 0.32$ & $6.07 \pm 0.25$ \\
\hline Mm. 1894 & CDIdI antigen (CdIdI) & NE & NE & NE & $1.56 \pm 0.01$ \\
\hline Mm.22673 & Fc receptor, IgE, high affinity I, gamma polypeptide (Fcer Ig) & NE & NE & $3.66 \pm 0.29$ & $3.38 \pm 0.63$ \\
\hline Mm.33263 & Histocompatibility 2, D region locus I (H2-DI) & NE & NE & $4.88 \pm 0.12$ & $9.04 \pm 1.15$ \\
\hline Mm.387।4I & Histocompatibility 2, D region locus 4 (H2-D4) & NE & NE & $8.92 \pm 7.66$ & $9.42 \pm 1.34$ \\
\hline Mm.35016 & Histocompatibility 2, T region locus 23 (H2-T23) & NE & NE & $4.72 \pm 0.89$ & $3.15 \pm 0.83$ \\
\hline Mm.29690I & Histocompatibility 2, Q region locus 7 (H2-Q7) & $4.55 \pm 2.49$ & $4.58 /-$ & $10.22 \pm 4.92$ & $9.50 \pm 0.76$ \\
\hline Mm.29690I & Histocompatibility 2, Q region locus $8(\mathrm{H} 2-\mathrm{Q} 8)$ & NE & NE & $4.45 \pm 0.48$ & NE \\
\hline
\end{tabular}

Genes that are involved in the virus response and immune response were upregulated at 72 and $96 \mathrm{hr}$ post infection concomitant with the virus appearance in the brain. Several inflammatory response and antigen presentation genes were upregulated and their expression increased with the progression of the disease. Values are fold changes in the gene expression in test samples over saline controls. Values are expressed as mean \pm SEM. NE indicates not expressed or expression was lower than I fold (and/or did not meet the cut off criteria of $99 \%$ confidence interval, 150 minimum intensity or $30 \mu \mathrm{m}$ spot size) NE indicates not expressed and '-' indicates not expressed in biological replicates.

immunodeficiency syndrome encephalitis and JC virus infection of the CNS $[20,21]$. Fc-receptors are important in antigen processing/presentation of myelin proteins during the autoimmune response in the CNS [22] and contribute to inflammatory damage in the CNS. Cd1d1 plays a critical role in the regulation of cytokine production after an acute virus infection [23]. Thus, in the current study, VEEV infection in mice induces a similar host immune response as observed with other viruses.

VEEV infection of the CNS has been shown to result in neurodegeneration, perivascular cuffing with infiltrating lymphocytes, gliosis, cerebral edema and apoptotic neurons associated with astrogliosis in the regions of the brain which is free of VEEV antigen [10]. Therefore, it is not clear whether VEEV is directly or indirectly involved with these changes. To understand this phenomenon we investigated whether the expression of chemokines, cytokines and other inflammatory genes is altered in VEEV infected brain. Interestingly, chemokines such as Cxcl9, Cxcl10, Cxcl11, Cxcl13, Ccl3, Ccl5 and Ccl12, Fcreceptor such as Fcer1g, and Mif genes were upregulated. These chemokines may contribute to the influx of neutrophils and lymphocytes as observed in the brain (Fig 2) and the severity of the encephalitis during VEEV infection. Fc-receptor,Fcerg1 may contribute in VEEV antigen presentation to $\mathrm{T}$ cells and induction of inflammatory cytokines. The cytokine expression at the site of inflammation is suggested to be the outcome of interaction of glucocorticoids and macrophage migration inhibitory factor (Mif) [24-26]. Though over-expressed in the microarray, only a marginal increase in expression of Mif was 
Table 4: Genes involved in apoptotic response in VEEV infected mice brain.

\begin{tabular}{|c|c|c|c|c|c|}
\hline \multirow[t]{2}{*}{ UniGene ID } & \multirow[t]{2}{*}{ Functional Grouping (Gene) } & \multicolumn{4}{|c|}{ Upregulation (fold change) (Hours post infection) } \\
\hline & & 24 & 48 & 72 & 96 \\
\hline & Apoptosis & & & & \\
\hline Mm.3336 & RIKEN cDNA I I I0007C09 gene (I I I0007C09Rik) & $2.66 \pm 1.63$ & $3.68 \pm 1.14$ & $6.81 \pm 4.35$ & $5.22 \pm 0.66$ \\
\hline Mm.277585 & amyloid beta (A4) precursor protein (ApP) & $2.50 \pm 0.48$ & $2.54 \pm 0.59$ & $4.05 \pm 1.20$ & $2.87 \pm 0.42$ \\
\hline Mm.84073 & Bcl2-associated athanogene 3 (Bag3) & $2.63 \pm 0.59$ & $3.30 \pm 0.43$ & $4.61 \pm 2.37$ & $4.23 \pm 0.18$ \\
\hline Mm.29820 & BCL2/adenovirus EIB I9kDa-interacting protein 3-like (Bnip3I) & $1.96 \pm 0.11$ & $2.52 \pm 0.04$ & $3.88 \pm 2.19$ & $3.07 \pm 0.14$ \\
\hline Mm.290908 & baculoviral IAP repeat-containing 6 (Birc6), mRNA. & $1.94 \pm 0.33$ & $2.15 \pm 0.22$ & $2.54 \pm 0.93$ & $2.18 \pm 0.04$ \\
\hline Mm.2837। 4 & sialophorin (Spn), mRNA. & $1.99 \pm 0.14$ & $2.50 \pm 0.19$ & $2.87 \pm 1.63$ & $2.25 \pm 0.24$ \\
\hline Mm.238I & amyloid beta (A4) precursor-like protein I (Aplpl), & NE & $1.90 \pm 0.06$ & $3.70 \pm 1.15$ & $2.27 \pm 0.14$ \\
\hline Mm.200608 & Clusterin (Clu) & NE & $1.74 \pm 0.13$ & $4.03 \pm 1.54$ & $2.45 \pm 0.37$ \\
\hline Mm. 136224 & interferon induced with helicase $\mathrm{C}$ domain I (Ifih I) & NE & $3.59 /-$ & $5.21 \pm 1.05$ & $4.18 \pm 0.31$ \\
\hline Mm.4266 & integral membrane protein $2 \mathrm{~B}$ (ltm2b) & NE & $1.55 \pm 0.20$ & $2.43 \pm 0.95$ & $2.46 \pm 0.54$ \\
\hline Mm.2326 & macrophage migration inhibitory factor (Mif) & NE & $1.08 \pm 0.17$ & $2.25 \pm 0.53$ & $2.06 \pm 0.07$ \\
\hline Mm.2775I8 & Monocyte to macrophage differentiation-associated (Mmd) & NE & $0.59 \pm 0.04$ & $2.33 \pm 0.45$ & $1.64 \pm 0.18$ \\
\hline Mm.347546 & Inositol 1,3,4-triphosphate 5/6 kinase & $\mathrm{NE}$ & $1.94 \pm 0.02$ & $0.95 \pm 0.05$ & $1.83 \pm 0.02$ \\
\hline Mm.285322 & mitochondrial carrier homolog I (C. elegans) (Mtchl) & NE & $0.95 \pm 0.01$ & $2.08 \pm 0.35$ & $1.77 \pm 0.23$ \\
\hline Mm.687 & Ras homolog gene family, member B (Rhob) & NE & $1.17 \pm 0.03$ & $2.48 \pm 0.87$ & $1.59 \pm 0.15$ \\
\hline Mm.379457 & Valosin containing protein (Vcp) & NE & $1.68 \pm 0.15$ & $2.04 \pm 0.77$ & $1.80 \pm 0.17$ \\
\hline Mm.6826 & Apoptosis-associated tyrosine kinase (Aatk) & NE & NE & $1.65 \pm 0.07$ & $1.20 \pm 0.43$ \\
\hline Mm.223689 & Bifunctional apoptosis regulator (Bfar) & NE & NE & $1.83 \pm 0.58$ & $1.70 \pm 0.08$ \\
\hline Mm. 130832 & caspase recruitment domain family, member I4 (Card I4) & NE & NE & $3.23 \pm 1.52$ & $2.69 \pm 0.08$ \\
\hline Mm.29028 & Death associated protein 3 (Dap3) & NE & NE & $1.87 \pm 0.14$ & $0.96 \pm 0.03$ \\
\hline Mm.280594 & Death effector domain-containing DNA binding protein 2 (Dedd2) & $\mathrm{NE}$ & NE & $1.79 \pm 0.66$ & $1.92 \pm 0.09$ \\
\hline Mm.37946I & eukaryotic translation initiation factor $5 \mathrm{~A}$ (Eif5a) & NE & NE & $2.61 \pm 0.49$ & $1.92 \pm 0.14$ \\
\hline Mm.342392 & $\begin{array}{l}\text { engulfment and cell motility I, ced-12 homolog (C. elegans) (Elmol), } \\
\text { transcript variant } 2\end{array}$ & $\mathrm{NE}$ & NE & $1.74 \pm 0.21$ & $1.41 \pm 0.08$ \\
\hline Mm.39760 & Fas apoptotic inhibitory molecule 2 (Faim2) & NE & NE & $2.85 \pm 1.23$ & $2.44 \pm 0.12$ \\
\hline Mm.28I298 & growth arrest and DNA-damage-inducible 45 gamma (Gadd45g) & NE & NE & $3.16 \pm 0.21$ & $2.12 \pm 0.05$ \\
\hline Mm. I55I0 & granzyme A (Gzma) & NE & NE & $1.27 \pm 0.41$ & $1.94 \pm 0.26$ \\
\hline Mm.2720 & Mitogen activated protein kinase 8 interacting protein I (Mapk8ip I) & NE & NE & $2.25 \pm 0.75$ & $1.16 \pm 0.19$ \\
\hline Mm. 1639 & Myeloid cell leukemia sequence I (Mcll) & NE & NE & $1.83 \pm 0.18$ & $1.56 \pm 0.09$ \\
\hline Mm.204876 & nucleolar protein 3 (apoptosis repressor with CARD domain) (Nol3) & NE & NE & $2.02 \pm 0.52$ & $1.84 \pm 0.09$ \\
\hline Mm.24I63 & PYD and CARD domain containing (Pycard) & NE & NE & $1.82 \pm 0.17$ & $1.38 \pm 0.18$ \\
\hline Mm.276325 & superoxide dismutase I, soluble (SodI) & NE & NE & $1.74 \pm 0.22$ & $1.54 \pm 0.24$ \\
\hline Mm.200792 & tumor necrosis factor receptor superfamily, member $2 I$ (Tnfrsf2I) & NE & NE & $2.37 \pm 0.84$ & $1.40 \pm 0.17$ \\
\hline Mm. 1894 & CDIdI antigen (CdIdI) & NE & NE & NE & $1.56 \pm 0.01$ \\
\hline Mm.217764 & phosphoglucomutase 2 (Pgm2)/ltgb3bp & NE & NE & NE & $1.63 \pm 0.11$ \\
\hline Mm.312628 & $\begin{array}{l}\text { Serine (or cysteine) proteinase inhibitor, clade A, member 3G } \\
\text { (Serpina3g) }\end{array}$ & NE & NE & $\mathrm{NE}$ & $2.83 \pm 0.18$ \\
\hline Mm.218473 & tumor differentially expressed I (Tdel)/Serinc3 & NE & NE & NE & $1.94 \pm 0.01$ \\
\hline Mm.338613 & forkhead box O3a (Foxo3a) & $1.92 \pm 0.17$ & NE & $2.26 \pm 1.08$ & $1.57 \pm 0.03$ \\
\hline Mm.22216 & TSC22 domain family $3(\operatorname{Tcs} 22 \mathrm{~d} 3)$ & NE & $1.63 \pm 0.20$ & NE & NE \\
\hline Mm. 1360 & growth arrest and DNA-damage-inducible 45 beta (Gadd45b) & NE & $2.00 \pm 0.33$ & NE & $1.85 \pm 0.03$ \\
\hline Mm.329277 & ubiquitin specific peptidase I4 (Usp I4)/Thocl & NE & $1.90 \pm 0.21$ & NE & $2.02 \pm 0.18$ \\
\hline Mm.347406 & CCAAT/enhancer binding protein (C/EBP), beta (Cebpb) & NE & NE & $2.01 \pm 0.17$ & NE \\
\hline Mm. 150 & Fc receptor, IgG, high affinity I (FcgrI) & NE & NE & $2.26 \pm 0.26$ & NE \\
\hline Mm.292100 & fibrinogen-like protein 2 (Fgl2) & NE & NE & $1.90 \pm 0.27$ & NE \\
\hline Mm.3685I5 & myc-like oncogene, s-myc protein (Mycs) & NE & NE & $3.11 \pm 0.05$ & NE \\
\hline
\end{tabular}

Genes that are modulated in the apoptotic response were upregulated at 72 and $96 \mathrm{hr}$ post infection concomitant with the virus appearance in the brain. Values are fold changes in the gene expression in test samples over saline controls. Values are expressed as mean \pm SEM. NE indicates not expressed or expression was lower than I fold (and/or didn't meet the cut off criteria of $99 \%$ confidence interval, I50 minimum intensity or $30 \mu \mathrm{m}$ spot size) and (-) indicates not expressed in biological replicates.

observed at $96 \mathrm{hr}$ post infection by PCR, where increases in inflammation and neutrophil migration were also observed.
Several apoptosis related genes were also upregulated.Clusterin (Clu), an anti-apoptotic factor, activates microglia to secrete neurotoxic agents [27]. Clu-activated 

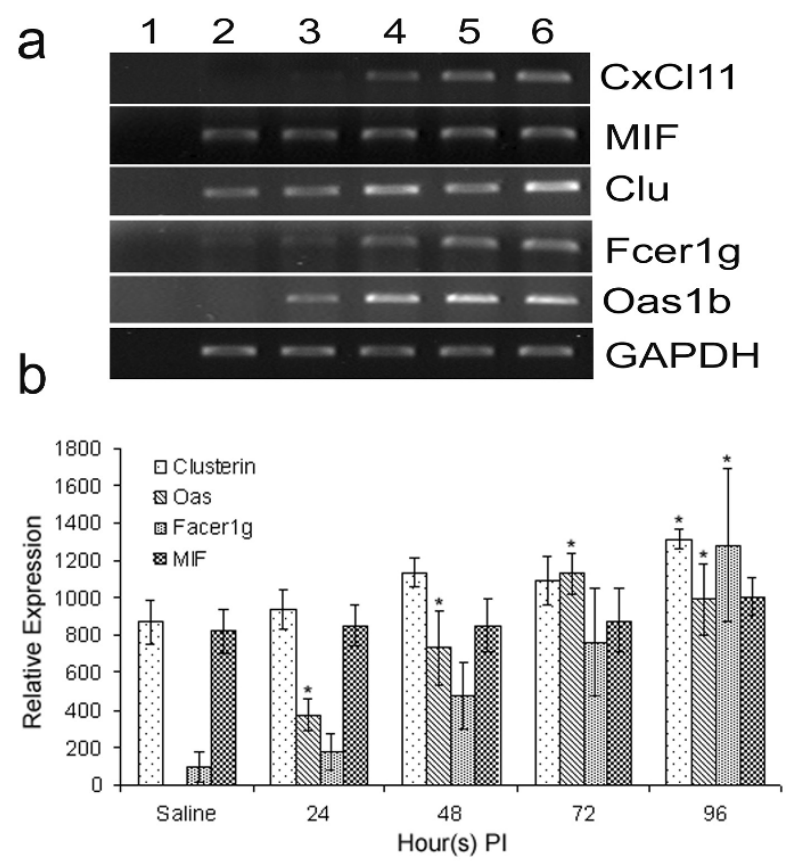

Figure 4

Confirmation of selected gene expression by RTPCR. (a) RT-PCR was performed for Oas Ib, Fcrelg, Clu and Mif genes. Expression was normalized with housekeeping gene GAPDH. Lane I: Negative control, Lane 2: uninfected saline control, Lane 3: $24 \mathrm{hr}$, Lane 4: $48 \mathrm{hr}$, Lane 5: $72 \mathrm{hr}$, Lane 6: $96 \mathrm{hr}$ post infection. (b) Quantitative estimation was done by densitometry analysis of PCR product using Scion Image Analysis Software (Scion Corporation, Frederick, Maryland 2I70I). Values were normalized to the corresponding values of the house keeping genes for individual samples. Values are expressed as mean \pm SEM. ${ }^{*} \mathrm{p} \leq 0.05$ compared to uninfected control.

microglia showed increased MHC class II expression, secreted reactive nitrogen intermediates and TNF- $\alpha$ [27]. VEEV infection of the brain also results in the activation of microglia $[11,17]$ and thus $\mathrm{Clu}$ may contribute to the gliosis observed in VEEV pathogenesis. The caspase recruitment domain (CARD) is a protein-binding module that mediates the assembly of CARD-containing proteins into apoptosis and NFKB signaling complexes [28]. CARD14, a membrane-associated guanylate kinase (MAGUK) family member containing CARD has been implicated in the antigen-specific signaling by the TCR complex via BCL10mediated NFKB activation [29]. In our study, CARD14 upregulation was concomitant with the increased inflammation and enhancement in apoptotic neurons. CARD14 may be involved in the VEEV antigen-initiated signaling in lymphocytes or glial cells and/or in the apoptotic pathways in neurons. Faim2 inhibits Fas-mediated apoptosis and helps in protecting foreign antigen-specific B cells during potentially hazardous interactions with FasL-bear- ing T cells [30]. Faim2 was upregulated following VEEV infection and may be involved in the activation and survival of immune cells in the brain. The paradoxical findings on the over-expression of pro-apoptotic CARD 14 and anti-apoptotic Faim2 may be due to their expression by different cell population in the brain.

\section{Conclusion}

Our results show a complex immune response to VEEV infection. Several pathways seem to interact for the final outcome of the disease. Thus, suppression of the inflammatory response and enhancement of the antiviral pathways may help in reducing the severity of the disease. We have identified several genes e.g., chemokines, Oas1b, Fcerg1, Mif and $\mathrm{Clu}$ which may provide potential targets for therapy against VEEV infection in the future.

\section{Methods Animals}

Six to ten week old male CD-1 mice were obtained from Charles River Laboratories, Wilmington, MA. Mice were housed in micro isolator cages and were provided food and water ad libitum. A $12 \mathrm{hr}$ light/dark cycle was maintained. All experiments were carried out in a bio-safety level 3 (BSL-3) facility and in accordance with the Guide for the Care and Use of Laboratory Animals (Committee on Care And Use of Laboratory Animals of The Institute of Laboratory Animal Resources, National Research Council, NIH Publication No. 86-23, revised 1996).

\section{Virus and Challenge Procedure}

A full length cDNA clone of VEEV subtype IA/B, V3000 [5] was used in the present study. Stock virus suspension was diluted in 1× Dulbecco's Phosphate Buffered Saline (DPBS) (Gibco BRL, Invitrogen Corporation Carlsbad, CA) supplemented with $0.1 \%$ fetal bovine serum (FBS) to 1,000 plaque forming units (pfu)/25 $\mu \mathrm{l}$. Mice were anesthetized lightly using inhalation anesthesia, isoflurane and $1000 \mathrm{pfu}$ of V3000 in $25 \mu \mathrm{l}$ volume was injected in the left rear footpad. Control animals were injected with $25 \mu$ of $1 \times$ DPBS supplemented with $0.1 \%$ FBS.

\section{Histopathology and Immunohistochemistry (IHC) for VEEV antigen}

Two animals from each group $(\mathrm{n}=10)$ were anesthetized using isoflurane and sacrificed at 24, 48, 72 and $96 \mathrm{hr}$ post infection (pi), control mice were sacrificed at $96 \mathrm{hr}$ pi. Brains were collected and the right brain hemisphere was fixed in $10 \%$ buffered neutral formalin (BNF) for 3-4 weeks. The left brain hemisphere was snap frozen at $80^{\circ} \mathrm{C}$. Tissues were then transferred into fresh BNF, routinely processed, and embedded in paraffin sections. Immunostaining was performed using rabbit polyclonal antiserum raised against VEEV (kindly provided by Cindy Rossi and Dr George Ludwig, USAMRIID) by an indirect 
avidin-biotin-immunoperoxidase technique (Vectastain $\mathrm{ABC}$ Elite, Vector laboratories, Burlingame, CA) as described before [31]. Briefly, sections were placed on poly-L-lysine coated slides, deparaffinized and hydrated. Endogenous peroxidase activity was blocked with 3\% hydrogen peroxide in methanol for $10 \mathrm{~min}$. Non-specific staining was blocked with $2.5 \%$ normal horse serum. Sections were incubated overnight with rabbit polyclonal antiserum against VEE virus $(1: 10000)$ at $4{ }^{\circ} \mathrm{C}$. To ascertain that the reaction of antibody was specific, sections from each test were incubated with normal serum IgG separately. Slides were washed with phosphate-buffered saline (PBS). Biotinylated secondary antibody IgG $(\mathrm{H}+\mathrm{L})$ was added and incubated for $30 \mathrm{~min}$. Sections were incubated with streptaavidin-peroxidase complex for $10 \mathrm{~min}$ and stained with diaminobenzidine (DAB) (Peroxidase substrate kit DAB, Vector laboratories, Burlingame, CA), counter stain used was Harris hematoxylin.

\section{Isolation of total RNA}

Frozen brain tissues were minced over ice and transferred to $1.5 \mathrm{ml}$ microfuge tubes. Total RNA was extracted using TriZol kit (Invitrogen life technologies, Carlsbad, CA) and quantitated spectrophotometrically using Beckman DU640 Spectrophotometer (Beckman instruments Inc., Columbia, MD, USA). RNA quality was determined electrophoretically on $1 \%$ agarose formaldehyde gel.

\section{Microarray studies}

High quality oligonucleotide glass arrays were produced containing a total of 16,463 seventy-mer oligonucleotides chosen from 750 bases of the 3' end of each ORF (open reading frame) (Operon Inc. Valencia, CA). These 16,463 oligonucleotides represent 15,000 genes. The high quality microarrays were produced in house (at CBER microarray laboratory) by spotting 70-mer oligonucleotides on polyL-lysine coated glass slides by Gene Machines robotics (Omnigrid, San Carlos, CA). The quality of printed arrays was confirmed as described [32]. Only high quality arrays that passed our quality control tests were used for these experiments. We have followed the MIAME (minimum information about a microarray experiment) guidelines for the presentation of our data [33]. Microarray was performed as described earlier [34]. Various steps involved in the microarray are as follows:

i) Probe preparation: Labeled cDNA probes were produced as described $[35,36]$. Briefly, $5 \mu \mathrm{g}$ of total RNA was dissolved in $12 \mu \mathrm{l}$ of DEPC water and incubated at $70^{\circ} \mathrm{C}$ for 5 minutes along with $1 \mu \mathrm{l}$ of aminoallyl-oligo dT (5' amino-modified) primer and quickly chilled for $3 \mathrm{~min}$ utes. Then, $2 \mu \mathrm{l} 10 \times$ first strand buffer, $1.5 \mu \mathrm{l} \mathrm{Stratascript}$

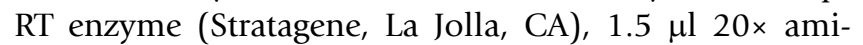
noallyl dUTP (mixture of $100 \mathrm{mM}$ dATP, dGTP, dCTP, dTTP from Invitrogen, Carlsbad, CA and $50 \mathrm{mM}$ ami- noallyl dUTP from Ambion, Austin, TX) and $2 \mu \mathrm{l}$ of $0.1 \mathrm{M}$ dithiothreitol (DTT, Invitrogen, Carlsbad, CA) were added and incubated for 90 minutes at $42^{\circ} \mathrm{C}$. After incubation, volume of the reaction mixture was raised to $60 \mu \mathrm{l}$ with $40 \mu \mathrm{l}$ of DEPC water.

cDNA was purified by MinElute column (Qiagen, Valencia, CA). $300 \mu \mathrm{l}$ of binding buffer PB was added to the coupled cDNA and mixed thoroughly. The mixture was applied to the MinElute column, and centrifuged for 1 min at max speed. After discharging the flow-through, 600 $\mu \mathrm{l}$ of washing buffer PE was added to the column, and centrifuged for $1 \mathrm{~min}$ at max speed. The flow-through was discharged and the washing repeated. The columns were then placed into a fresh eppendorf tube and $10 \mu \mathrm{l}$ elution buffer added to the center of the membrane, incubated for $1 \mathrm{~min}$ at room temperature, centrifuged for $1 \mathrm{~min}$ at max speed and probes were collected. Finally, $3 \mu \mathrm{l}$ of $2 \times$ coupling buffer ( $1 \mathrm{M} \mathrm{NaHCO} 3, \mathrm{pH} 9.0)$ and $5 \mu \mathrm{l} \mathrm{Cy} 3$ and 5 ul Cy5 (Amersham Biosciences, UK) dye mixed into eluted buffers derived from both saline and VEE infected samples respectively and incubated at room temperature in dark for 90 minutes. Saline control probes were labeled with $\mathrm{Cy} 3$ and probe from VEEV infected samples were labeled with Cy5. After incubation, the volume was raised to $60 \mu \mathrm{l}$ by DEPC water and then CDNA was purified by MinElute column and eluted with $13 \mu$ l elution buffer by centrifugation.

ii) Hybridization: For hybridization, $36 \mu$ l hybridization mixture [26 $\mathrm{l}$ cDNA mixture, $1 \mu \mathrm{l}(10 \mu \mathrm{g})$ COT-1 DNA, 1 $\mu \mathrm{l}(8-10 \mu \mathrm{g})$ poly(dA), $1 \mu \mathrm{l}$ yeast tRNA $(4 \mu \mathrm{g}), 6 \mu \mathrm{l} 20 \times$ SSC and $1 \mu \mathrm{l} 10 \%$ SDS] was pre-heated at $100^{\circ} \mathrm{C}$ for 2 minutes and cooled for 1 minute. Total volume of probe was added on the array and covered with cover slip (22 $\mathrm{mm} \times 40 \mathrm{~mm}$ ). Slides were placed in hybridization chamber (Genemachines) and $20 \mu \mathrm{l}$ water was added to far end of slide (to maintain humidity), and incubated overnight $(10-16 \mathrm{hr})$ at $65^{\circ} \mathrm{C}$. Slides were then washed for $2 \mathrm{~min}$ utes each into $2 \times$ SSC, $1 \times$ SSC and $0.1 \times$ SSC and spindried.

iii) Data filtration, normalization, and analysis: Microarray slides were scanned in both Cy3 $(532 \mathrm{~nm})$ and Cy5 (635 nm) channels using Axon GenePix 4000B scanner (Axon Instruments, Inc., Foster City, CA) with a 10micron resolution. Scanned microarray images were exported as TIFF files to GenePix Pro 5.1 software for image analysis. The raw images were collected at 16-bit/ pixel resolutions with 0 to 65,535 count dynamic range. The area surrounding each spot image was used to calculate a local background and subtracted from each spot before $\mathrm{Cy} 5: \mathrm{Cy} 3$ ratio calculation. The average of the resulting total $\mathrm{Cy} 3$ and $\mathrm{Cy} 5$ signal gave a ratio that was used to normalize the signals. Each microarray experi- 
ment was globally normalized to make the median value of the log2-ratio equal to zero. The normalization process corrects for dye bias, PMT (Photo multiplier tube) voltage imbalance, and variations between channels in the amounts of the labeled cDNA probes hybridized. The data files representing the differentially expressed genes were then created.

For advanced data analysis, data files (in gpr format) and image (in jpeg format) were imported into mAdb (microarray database, Center for Information Technology, National Cancer Institute, Bethesda, MD, USA), and normalized by software tools provided by National Institutes Health, Center for Information Technology. Spots with $\geq 1.5$ fold higher expression with at least 150 -fluorescence intensity in either channel or $30 \mu \mathrm{m}$ spot size were considered as good quality spots for analysis with additional filtration. These advanced filters prevented the potential effect of the poor quality spots in data analysis. All VEEV infected samples from four different time points were hybridized in duplicates (biological replicate). The data were further analyzed by Gene Ontology for Functional Analysis (GOFFA) Library of Arraytrack software [36].

\section{Reverse Transcription (RT) and Polymerase Chain Reaction (PCR)}

cDNA was synthesized using the Superscript first strand synthesis system for RT-PCR kit (Invitrogen Inc. Carlsbad, CA). Briefly, primer mix (1ugRNA, dNTP, oligo dts) was incubated at $65^{\circ} \mathrm{C}$ for 5 min then mixed with reaction mixture (10× PCR buffer, $25 \mathrm{mM} \mathrm{MgCl}_{2}, 0.1 \mathrm{M} \mathrm{DTT}$, RNase inhibitor) and incubated at $42^{\circ} \mathrm{C}$ for $2 \mathrm{~min}$. cDNA synthesis was done using RT enzyme (SSII) at $42^{\circ} \mathrm{C}$ for 50 $\min$. The reaction was stopped by incubating at $70^{\circ} \mathrm{C}$ for 15 min. Residual RNA was digested by E. coli RNase $\mathrm{H}$ at $37^{\circ} \mathrm{C}$ for $20 \mathrm{~min}$ and samples were stored at $-20^{\circ} \mathrm{C}$. PCR was performed to validate few of the genes that were identified in the microarray. Primers and conditions used for the different genes are as follows. Clu: forward primer (BC075668.1: 36-52) 5'GACTCCAGATTCCAAGG'3, reverse primer (BC075668.1: 419-401) 5'GGTATGCTTCAGGCAGGGC'3 $\left(95^{\circ} \mathrm{C} / 30 \mathrm{~s}, 50^{\circ} \mathrm{C} / 45 \mathrm{~s}, 72^{\circ} \mathrm{C} / 45 \mathrm{~s}: 20\right.$ cycles),; Oas1b: forward primer (BC012877.1: 250-266) 5'GCTCAAGGGCAGGTCAG'3, reverse primer (BC012877.1: 652-635) 5'GGTTGGGCGACAGTTCAG'3 $\left(95^{\circ} \mathrm{C} / 30\right.$ s, $52^{\circ} \mathrm{C} / 45$ s, $72^{\circ} \mathrm{C} / 45$ s: 22 cycles); Mif: forward primer (NM_010798.2: 19-37) 5'CTGGCTTGGGTCACACCGC'3, reverse primer (NM_010798.2: 383-367) 5 'CGTAATAGTTGATGTAG' $3 \quad\left(95^{\circ} \mathrm{C} / 30\right.$ s, $45^{\circ} \mathrm{C} / 45$ s, $72^{\circ} \mathrm{C} / 45$ s: 23 cycles); Fcer1g: forward primer (NM_010185.4: 207-225) 5'TATGGTATTGTCCTTAC'3, reverse primer (NM_010185.4: 429-412) 5'CCAAGAGGGCTCGGAGAG'3 $\left(95^{\circ} \mathrm{C} / 30 \mathrm{~s}, 49^{\circ} \mathrm{C} / 45\right.$ s, $72^{\circ} \mathrm{C} / 45$ s: 23 cycles); CxCl11 primer mix was purchased from Superarray Bioscience Corporation, Frederic MD, RefSeq Acces- sion \# NM_019494.1, position 693-713 (95 ${ }^{\circ} \mathrm{C} / 30 \mathrm{~s}$, $55^{\circ} \mathrm{C} / 45$ s, $72{ }^{\circ} \mathrm{C} / 45$ s: 23 cycles); GAPDH: forward primer $5^{\prime}$ CCATCACCATCTTCCAGGAGCGAG'3, reverse primer 5'CACAGTCTTCTGGGTGGCAGTGAT' $3\left(95^{\circ} \mathrm{C} / 30\right.$ s, $52^{\circ} \mathrm{C} / 45 \mathrm{~s}, 72^{\circ} \mathrm{C} / 45 \mathrm{~s}$ : 25 cycles). PCR products were visualized by electrophoreses over $1.2 \%$ agarose gel and staining with ethidium bromide. Specific amplification was determined by comparing the product size on gel relative to known DNA molecular weight marker. Further PCR products were sequenced and checked for specific amplification by blasting the sequence in the NCBI genome database. Briefly, PCR products were pooled from 72 and $96 \mathrm{hr}$ for each sample and purified using spin QIAprep Spin Miniprep kit (Qiagen Inc. USA, Valencia, CA). Sequencing reaction was done using BigDye Version 2.1(Applied Biosystems, Foster City, CA). Product was then purified using Performa ${ }^{\circledR}$ DTR Gel Filtration Cartridges (Edge BioSystems, Gaithersburg, MD). Sequencing was done in in-house facility on DNA Sequencer 3100 (Applied Biosystems, Foster City, CA).

\section{Abbreviations}

VEEV: Venezuelan equine encephalitis virus; CNS: Central nervous system; MIAME: Minimum information about a microarray experiment; IHC: Immunohistochemistry; pfu: Plaque forming unit; H\&E: Hematoxilin and Eosin; MST: Mean survival time; TCR: T-cell receptor; BBB: Blood brain barrier; AP: Antigen presentation.

\section{Authors' contributions}

AS conducted the mouse experiments, IHC, histology, RNA isolation, RT-PCR, sequencing and drafted the manuscript. BB carried out microarrays and initial data analysis using different software and participated in drafting of the manuscript. AS and BB participated in microarray analysis. RKP and RKM conceived of the study, and participated in its design and coordination and helped to draft the manuscript. All authors read and approved the final manuscript.

\section{Additional material}

\section{Additional file 1}

Supplementary table-1: Down modulated genes in VEEV infected mice brain. Values are expressed as mean \pm SEM. "-" indicates not expressed in biological replicates.

Click here for file

[http://www.biomedcentral.com/content/supplementary/14712164-9-289-S1.doc]

\section{Acknowledgements}

This work was supported by grants from the US Army Medical Research and Material Command (DAMD 17-99-I-9484), Defense Threat Reduction Agency project number 4.10019_07_US_B and US-India Foreign Currency 
Fund from the U.S. Department of State. Authors are grateful to Dr. Clifford Snapper for critically reading the manuscript. The opinions or assertions contained herein are the scientific views of the authors and should not be construed as official or necessarily reflecting the views of the Uniformed Services University of the Health Sciences or the Department of Defense, USA or Food and Drug Administration, USA.

\section{References}

I. Weaver SC, Ferro C, Barrera R, Boshell J, Navarro JC: Venezuelan equine encephalitis. Annu Rev Entomol 2004, 49: 141-174.

2. Hawley RJ, Eitzen EM Jr: Biological weapons - a primer for microbiologists. Annu Rev Microbiol 200I, 55:235-253.

3. Bigler WJ, Ventura AK, Lewis AL, Wellings FM, Ehrenkranz NJ: Venezuelan equine encephalomyelitis in Florida: endemic virus circulation in native rodent populations of Everglades hammocks. Am J Trop Med Hyg 1974, 23(3):5I3-52.

4. Jackson AC, SenGupta SK, Smith JF: Pathogenesis of Venezuelan equine encephalitis virus infection in mice and hamsters. Vet Pathol 199|, 28(5):410-4|8.

5. Grieder FB, Davis NL, Aronson JF, Charles PC, Sellon DC, Suzuki K Johnston RE: Specific restrictions in the progression of Venezuelan equine encephalitis virus-induced disease resulting from single amino acid changes in the glycoproteins. Virology 1995, 206(2):994-1006.

6. Grieder FB, Davis BK, Zhou XD, Chen SJ, Finkelman FD, Gause WC: Kinetics of cytokine expression and regulation of host protection following infection with molecularly cloned Venezuelan equine encephalitis virus. Virology 1997, 233(2):302-312.

7. Charles PC, Walters E, Margolis F, Johnston RE: Mechanism of neuroinvasion of Venezuelan equine encephalitis virus in the mouse. Virology 1995, 208(2):662-67I.

8. Charles PC, Trgovcich J, Davis NL, Johnston RE: Immunopathogenesis and immune modulation of Venezuelan equine encephalitis virus-induced disease in the mouse. Virology $200 \mathrm{I}$, 284(2): 190-202.

9. Ryzhikov AB, Ryabchikova El, Sergeev AN, Tkacheva NV: Spread of Venezuelan equine encephalitis virus in mice olfactory tract. Arch Virol 1995, I 40( I 2):2243-2254.

10. Schoneboom BA, Fultz MJ, Miller TH, McKinney LC, Grieder FB: Astrocytes as targets for Venezuelan equine encephalitis virus infection. / Neurovirol I 999, 5(4):342-354.

11. Schoneboom BA, Catlin KM, Marty AM, Grieder FB: Inflammation is a component of neurodegeneration in response to Venezuelan equine encephalitis virus infection in mice. J Neuroimmunol 2000, 109(2): I32-146.

12. Steele KE, Seth P, Catlin-Lebaron KM, Schoneboom BA, Husain MM, Grieder F, Maheshwari RK: Tunicamycin enhances neuroinvasion and encephalitis in mice infected with venezuelan equine encephalitis virus. Vet Pathol 2006, 43(6):904-9/3.

13. Jackson AC, Rossiter JP: Apoptotic cell death is an important cause of neuronal injury in experimental Venezuelan equine encephalitis virus infection of mice. Acta Neuropathol (Berl) 1997 93(4):349-353.

14. Kajaste-Rudnitski A Mashimo T, Frenkiel MP, Guenet IL Lucas M, Despres $P$ : The 2',5'-oligoadenylate synthetase I $\mathbf{b}$ is a potent inhibitor of West Nile virus replication inside infected cells. | Biol Chem 2006, 28 I (8):4624-4637.

15. Grieder FB, Vogel SN: Role of interferon and interferon regulatory factors in early protection against Venezuelan equine encephalitis virus infection. Virology 1999, 257(I): 106-II8.

16. White LJ, Wang JG, Davis NL, Johnston RE: Role of alpha/beta interferon in Venezuelan equine encephalitis virus pathogenesis: effect of an attenuating mutation in the $5^{\prime}$ untranslated region. J Virol 200I, 75(8):3706-37I8.

17. Schoneboom BA, Lee JS, Grieder FB: Early expression of IFNalpha/beta and iNOS in the brains of Venezuelan equine encephalitis virus-infected mice. J Interferon Cytokine Res 2000 , 20(2):205-2I5.

18. O'Keefe GM, Nguyen VT, Benveniste EN: Regulation and function of class II major histocompatibility complex, CD40, and B7 expression in macrophages and microglia: Implications in neurological diseases. J Neurovirol 2002, 8(6):496-5।2.
19. Dorries $\mathrm{R}$ : The role of T-cell-mediated mechanisms in virus infections of the nervous system. Curr Top Microbiol Immunol 200I, 253:219-245

20. Achim CL, Morey MK, Wiley CA: Expression of major histocompatibility complex and HIV antigens within the brains of AIDS patients. Aids 199I, 5(5):535-54I.

21. Achim CL, Wiley CA: Expression of major histocompatibility complex antigens in the brains of patients with progressive multifocal leukoencephalopathy. J Neuropathol Exp Neurol I992, 5 I (3):257-263

22. Abdul-Majid KB, Stefferl A, Bourquin C, Lassmann H, Linington $C$, Olsson T, Kleinau $S$, Harris RA: Fc receptors are critical for autoimmune inflammatory damage to the central nervous system in experimental autoimmune encephalomyelitis. Scand I Immunol 2002, 55(I):70-8I.

23. Roberts TJ, Lin Y, Spence PM, Van Kaer L, Brutkiewicz RR: CDId Idependent control of the magnitude of an acute antiviral immune response. J Immunol 2004, I 72(6):3454-346I.

24. Bucala R: Neuroimmunomodulation by macrophage migration inhibitory factor (MIF). Ann N Y Acad Sci 1998, 840:74-82.

25. Baugh JA, Donnelly SC: Macrophage migration inhibitory factor: a neuroendocrine modulator of chronic inflammation. J Endocrinol 2003, I79(I): I5-23.

26. Tanino Y, Makita H, Miyamoto K, Betsuyaku T, Ohtsuka Y, Nishihira J, Nishimura M: Role of macrophage migration inhibitory factor in bleomycin-induced lung injury and fibrosis in mice. Am J Physiol Lung Cell Mol Physiol 2002, 283(I):LI56-I62.

27. Xie Z, Harris-White ME, Wals PA, Frautschy SA, Finch CE, Morgan TE: Apolipoprotein J (clusterin) activates rodent microglia in vivo and in vitro. J Neurochem 2005, 93(4): 1038-1046.

28. Bertin J, Wang L, Guo Y, Jacobson MD, Poyet JL, Srinivasula SM, Merriam S, DiStefano PS, Alnemri ES: CARDII and CARDI4 are novel caspase recruitment domain (CARD)/membraneassociated guanylate kinase (MAGUK) family members that interact with BCLIO and activate NF-kappa B. J Biol Chem 200I, 276(15): I I877-I | 882

29. Pomerantz JL, Denny EM, Baltimore D: CARD I I mediates factorspecific activation of NF-kappaB by the T cell receptor complex. Embo J 2002, 2 I(19):5184-5194.

30. Rothstein TL: Inducible resistance to Fas-mediated apoptosis in B cells. Cell Res 2000, 10(4):245-266.

31. Sharma A, Singh AK, Warren J, Thangapazham RL, Maheshwari RK: Differential regulation of angiogenic genes in diabetic wound healing. J Invest Dermatol 2006, I 26( I 0):2323-233 I.

32. Amy XY, Mejido J, Petersen D, Han J, Kawasaki ES, Puri RK: Quality Analysis of Contact-Pin Fabricated Oligonucleotide Microarrays. Molecular Biotechnology 2006 in press.

33. Brazma A Hingamp $P$, Quackenbush J. Sherlock G, Spellman P, Stoeckert C, Aach J, Ansorge W, Ball CA, Causton HC, Gaasterland T, Glenisson P, Holstege FC, Kim IF, Markowitz V, Matese JC, Parkinson H, Robinson A, Sarkans U, Schulze-Kremer S, Stewart J, Taylor R, Vilo J, Vingron M: Minimum information about a microarray experiment (MIAME)-toward standards for microarray data. Nat Genet 200I, 29(4):365-37I.

34. Bhattacharya B, Miura T, Brandenberger R, Mejido J, Luo Y, Yang AX, Joshi BH, Ginis I, Thies RS, Amit M, Lyons I, Condie BG, ItskovitzEldor J, Rao MS, Puri RK: Gene expression in human embryonic stem cell lines: unique molecular signature. Blood 2004, I03(8):2956-2964

35. Risinger JI, Maxwell GL, Chandramouli GV, Jazaeri A, Aprelikova O, Patterson T, Berchuck A, Barrett IC: Microarray analysis reveals distinct gene expression profiles among different histologic types of endometrial cancer. Cancer Res 2003, 63(I):6-II.

36. Han J, Lee H, Nguyen NY, Beaucage SL, Puri RK: Novel multiple 5'amino-modified primer for DNA microarrays. Genomics 2005, 86(2):252-258

37. Sun H, Fang H, Chen T, Perkins R, Tong W: GOFFA: Gene Ontology For Functional Analysis - A FDA Gene Ontology Tool for Analysis of Genomic and Proteomic Data. BMC Bioinformatics 2006, 7(Suppl 2):S23. 